\title{
Caracterização de sintomas visuais de deficiência de micronutrientes em tomateiro do grupo salada
}

\section{Characterization of visual symptoms of micronutrient deficiencys of "salada" group tomato plants}

\author{
Rosa Honorato de Oliveira ${ }^{1 *}$; Myrne Jamilly Souza Lima²; Hercílio de Assis \\ Pereira-Junior ${ }^{3}$; Tiyoko Nair Hojo Rebouças ${ }^{4}$; Otoniel Magalhães Morais ${ }^{4}$; \\ Bruno Vinícius Castro Guimarães ${ }^{3}$; Cláudio Azevedo Nolasco ${ }^{5}$
}

\section{Resumo}

\begin{abstract}
Este experimento foi conduzido em casa de vegetação da Universidade Estadual do Sudoeste da Bahia Vitória da Conquista com o objetivo de caracterizar os sintomas visuais de deficiência de micronutrientes em um híbrido de tomateiro do grupo salada, cultivado em solução nutritiva. Os tratamentos foram: completo, omissão de B, omissão de Zn, omissão de Mn, omissão de Mo, omissão de Fe e omissão de $\mathrm{Cu}$. Com exceção da omissão de $\mathrm{Cu}$, as demais omissões resultaram em alterações morfológicas com sintomas característicos. Os sintomas ocorreram primeiramente, e com maior intensidade nas deficiências de $\mathrm{Fe}$ e $\mathrm{Zn}$. A seqüência de surgimento de sintomas foi a seguinte: $\mathrm{Fe}, \mathrm{Zn}, \mathrm{Cu}, \mathrm{Mn}$, Mo, B. A deficiência de $\mathrm{Zn}$ promoveu a rachadura no fruto e de B promoveu a podridão apical do fruto de tomate.
\end{abstract}

Palavras-chave: Lycopersicon esculentum Mill, sintomatologia, solução nutritiva

\begin{abstract}
The aim of this research work was to characterize the visual symptoms of micronutrient deficiencies of tomato plants. A greenhouse experiment with nutrient solutions was used with "Salada" group tomato hybrid plants. Treatments were as follows: complete, minus B, minus $\mathrm{Zn}$, minus $\mathrm{Mn}$, minus Mo, minus $\mathrm{Fe}$, and minus $\mathrm{Cu}$. Except the omission of $\mathrm{Cu}$, the other omissions resulted in morphological alteration with peculiar symptoms. The symptoms occurred firstly and had highest intensity when either Fe or $\mathrm{Zn}$ was deficient. The sequence of symptoms was $\mathrm{Fe}, \mathrm{Zn}, \mathrm{Cu}, \mathrm{Mn}, \mathrm{Mo}$ and $\mathrm{B}$. The $\mathrm{Zn}$ deficiency caused fruit cracking and the B omition caused blossom-end rot.
\end{abstract}

Key words: Lycopersicon esculentum, sintomatology, nutrient solution

1 Profa. Adjunto I da UFRPE/UAST. Caixa Postal 063, CEP 56900-000, Serra Talhada - PE, E-mail: honorato@uast.ufrpe.br.

2 Mestre em Agronomia pelo UESB, Campus de Vitória da Conquista. Estrada do Bem Querer, km 04, Caixa Postal 95, CEP: 45083-900. Vitória da Conquista, BA, E-mail: mjmyrne@yahoo.com.br

3 Discente do Curso da UESB. Campus de Vitória da Conquista, Estrada do Bem Querer, km 04, Caixa Postal 95, CEP: $45083-900$. Vitória da Conquista, BA, E-mail: herciliojunior@yahoo.com.br / bvinicius20@yahoo.com.br

4 Prof. Adjunto UESB, Departamento de Fitotecnia e Zootecnia, Campus de Vitória da Conquista, Estrada do Bem Querer, km 04, Caixa Postal 95, CEP: 45083-900. Vitória da Conquista, BA, E-mail:tiyoko@uesb.br

5 Engenheiro Agrônomo, Mestre. Nilson Gonçalves, 584. Guarani. CEP: 45035370. Vitória da Conquista-BA, E-mail; agrocn@ hotmail.com

* Autor para correspondência 


\section{Introdução}

Considerando-se os aspectos sócio-econômicos, a cultura do tomateiro (Lycopersicon esculentum Mill), é hoje, dentre as hortaliças mais produzidas no Brasil, a mais importante (RODRIGUES et al., 2002). De acordo com diversos autores, os solos cultivados com esta cultura apresentam características completamente diferentes, com sérias implicações na recomendação de uso de fertilizantes e corretivos.

A carência de cada elemento considerado essencial para o crescimento das plantas desencadeia determinados fenômenos bioquímicos dentro das plantas, os quais são externados por sintomas típicos (EPSTEIN, 1972).

De acordo com Molina (1997) o diagnóstico de problemas nutricionais, mediante a observação de sintomas, tem grande importância prática porque permite tomar decisões rápidas no campo para a correção das deficiências.

Embora a possibilidade de ocorrer carência de um micronutriente seja menor do que um macronutriente de acordo com Raij (1991) é necessário aprofundar os conhecimentos sobre as reais necessidades do tomateiro em micronutrientes. Esta cultura se destaca, dentre as olerícolas como uma das mais exigentes em micronutrientes (CASTELLANE; SOUZA, MESQUITA FILHO, 1991). Segundo Rodrigues et al. (2002) a ordem de absorção de nutrientes pelo tomateiro é Fe, $\mathrm{Zn}, \mathrm{B}, \mathrm{Mn}$ e $\mathrm{Cu}$.

Uma das maneiras práticas de detectar o elemento limitante, além da diagnose foliar é por meio do aspecto visual das plantas, considerando-se que as deficiências minerais promovem alterações no metabolismo, as quais frequentemente modificam os aspectos morfológicos e anatômicos (SILVEIRA et al., 2002). Na literatura são escassos trabalhos visando obter a caracterização de sintomas visuais de deficiência de micronutrientes em tomateiro, justificando o desenvolvimento desta pesquisa.

Com base nessas informações o presente trabalho teve como objetivo estudar aspectos relacionados a nutrição mineral do tomateiro cultivado em solução nutritiva.

\section{Material e Métodos}

Com o objetivo de induzir o aparecimento de sintomas de deficiência de micronutrientes em um híbrido de tomateiro do grupo salada, este experimento foi conduzido em casa de vegetação da Universidade Estadual do Sudoeste da Bahia, Campus de Vitória da Conquista - BA. As mudas foram produzidas em bandejas de isopor de 128 células, utilizando substrato comercial e, foram transplantadas para vasos de seis litros, quando atingiram dois pares de folhas verdadeiras. Foi utilizada uma solução nutritiva adaptada para tomate associada a solução de Hoagland e Arnon (1950). As plantas passaram por um período de adaptação e uniformização durante uma semana, recebendo uma solução nutritiva completa de $1 / 3$ da concentração iônica, para posteriormente receber os tratamentos com $1 / 2$ da concentração, na primeira semana e, daí por diante com 1 força. As plantas foram conduzidas em haste única e com tutor. Os tratamentos constaram de: Completo; omissão de B, omissão de Zn, omissão de Mn, omissão de Mo, omissão de Fe e omissão de $\mathrm{Cu}$, distribuídos em delineamento experimental de blocos casualizados com quatro repetições, com uma unidade experimental sendo representada por um vaso com uma planta.

As soluções foram preparadas com reagentes p.a diluídos em água deionizada. O volume de solução nos vasos era completado diariamente com água deionizada e toda a solução era renovada em intervalos de 15 dias.

$\mathrm{O}$ pH da solução era medido semanalmente e mantido em torno de 5,5- 6,4, utilizando $\mathrm{NaOH}$ a $0,01 \mathrm{~N}$ ou $\mathrm{HCl}$ a 0,01 , conforme a necessidade. As raízes das plantas foram permanentemente aeradas com auxílio de um compressor de ar, do qual saía uma mangueira central, de onde derivavam mangueiras 
de menor diâmetro que ficavam submersas na solução através de um furo na placa de isopor. A fixação das plantas foi feita por espumas presas em furos nas placas que serviam de tampa para os vasos. O experimento foi mantido por tempo suficiente até o quadro sintomatológico tornar-se evidente. A evolução dos sintomas de deficiência dos elementos minerais foi descrita e fotografada, a partir da instalação até tornaram-se bem definidos. Para alguns tratamentos as plantas foram mantidas até a frutificação quando se procedeu a coleta do experimento.

\section{Resultados e Discussão}

Houve notável diferença na expressão dos sintomas de deficiência dos micronutrientes omitidos. Alguns expressaram sintomas típicos no período vegetativo, poucos dias após a omissão, que foram se agravando com a evolução da deficiência. Alguns micronutrientes, porém, revelaram sintomas principalmente na fase de frutificação, ao passo que, outros não expressaram sintomas característicos de deficiência nutricional. Desse modo, a magnitude de resposta dos micronutrientes variou com sua exigência pela cultura.

O tratamento com omissão de Fe foi o primeiro a expressar sintomas de deficiência, cerca de 3 a 4 dias após a omissão do nutriente. As folhas novas apresentavam clorose que se iniciava na base do pecíolo e caminhando em direção à ponta das folhas (Figura 1A e 1B). Embora os sintomas tenham se iniciado pelas folhas novas, com o aumento do tempo de deficiência, a clorose atingiu também as folhas velhas, de modo que a planta inteira tornou-se clorótica e no final do ciclo, as folhas apresentavam-se totalmente esbranquiçadas (Figura $1 \mathrm{C}$ e 1D). As plantas cultivadas nessa condição apresentavam ainda baixo desenvolvimento, com caules levemente arroxeados e menor produção de folhas. O sistema radicular mostrou-se escurecido, sem ramificações secundárias, apresentando raízes
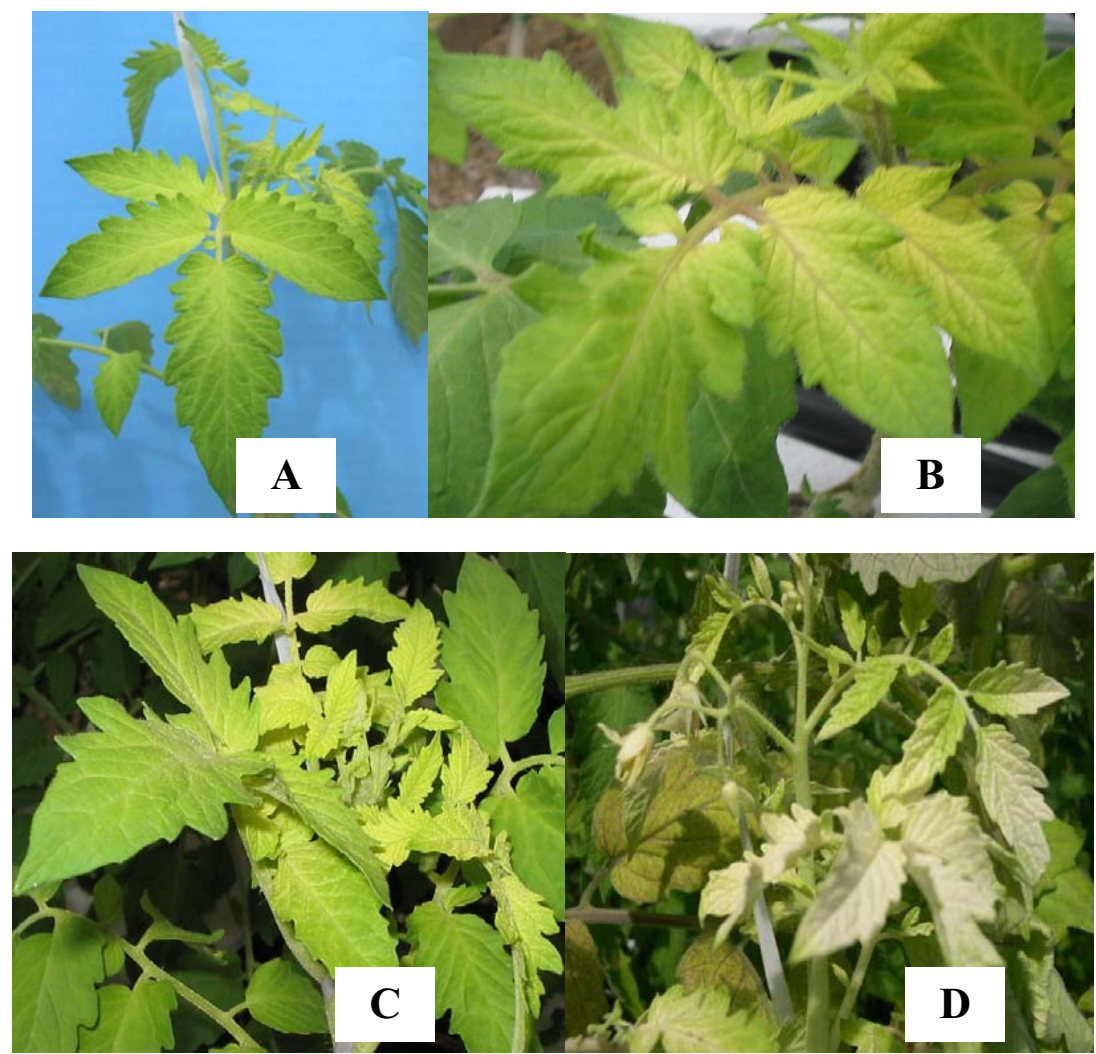

Figura 1. Evolução de sintomas de deficiência de ferro em tomateiro. 
curtas e grossas. Praticamente não foi observado florescimento nestas plantas. Assim, o crescimento da planta foi completamente prejudicado pela ausência do nutriente, denotando a importância do ferro na cultura do tomateiro. Com a deficiência de Fe nas plantas, ocorre uma clorose geral das folhas, que depois se tornam esbranquiçadas. No princípio, as nervuras podem permanecer verdes, mas na maioria das espécies, elas também se tornam cloróticas (EPSTEIN, 1972).

De acordo com Malavolta, Vitti e Oliveira (1997) a clorose provocada pela deficiência de Fe é causada, possivelmente pela redução na produção de clorofila na planta. Romheld (2001) salienta que os sintomas de clorose podem ter sido causados por um distúrbio na estrutura do cloroplasto, como conseqüência da inibição na síntese de lipídios. Estes sintomas coincidem com aqueles obtidos por Salvador, Moreira e Muraoka (1999) e Lange et al. (2005) quando estudaram a omissão de Fe em gaiabeira e mamoneira, respectivamente.

As primeiras alterações morfológicas resultantes da deficiência de $\mathrm{Zn}$ começaram a surgir 15 após a omissão do nutriente. Os sintomas

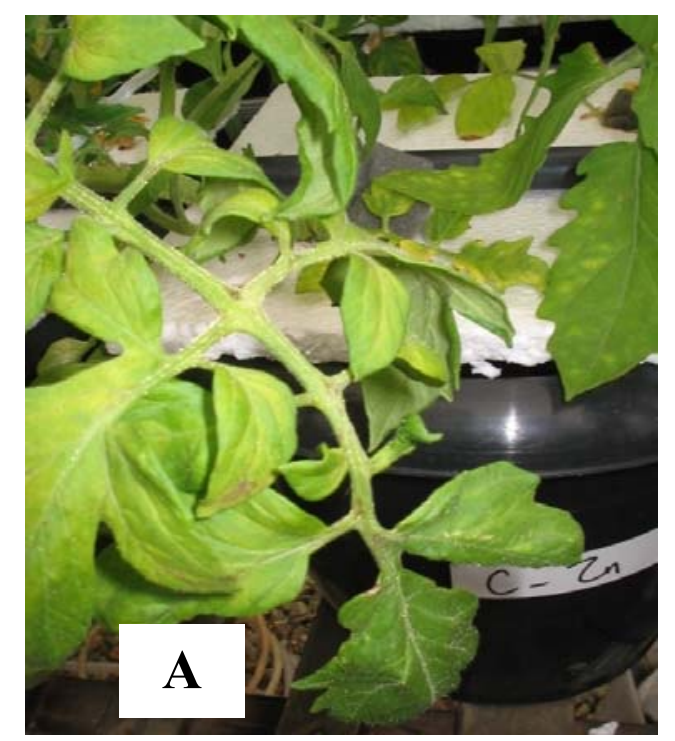

manifestaram-se inicialmente nas folhas novas, as quais apresentavam clorose leve (Figura 2A), porém, sem alteração no desenvolvimento das plantas. Com a intensificação da deficiência, toda a planta foi atingida, mostrando folhas cloróticas, coreáceas e encarquilhadas, encurtamento das nervuras e engrossamento do pecíolo (Figura 2B). A deficiência de $\mathrm{Zn}$ compromete importantes eventos fisiológicos e, consequentemente, o crescimento e desenvolvimento da planta (ZABINI et. al., 2007). De acordo com Marschner (1995) a deficiência de $\mathrm{Zn}$ leva a uma redução na atividade da enzima $\mathrm{Cu} /$ $\mathrm{Zn}$ superóxido desmutase (Cu/ZnSOD) favorecendo o incremento dos danos oxidativos, ocasionando o diminuição no teor de clorofila.Com a intensificação da deficiência o sistema radicular também foi afetado. As raízes apresentavam-se escurecidas, mais grossas e sem ramificações laterais, a exemplo daquelas deficientes em Fe. Dessa forma, ao final do experimento, as plantas submetidas à deficiência de $\mathrm{Zn}$ apresentavam folhas em tons arroxeados na margem ao longo de toda a extensão da mesma (Figura 2B). Este sintoma também foi observado por Santi et al. (2005) testando omissão de zinco em sorgo.

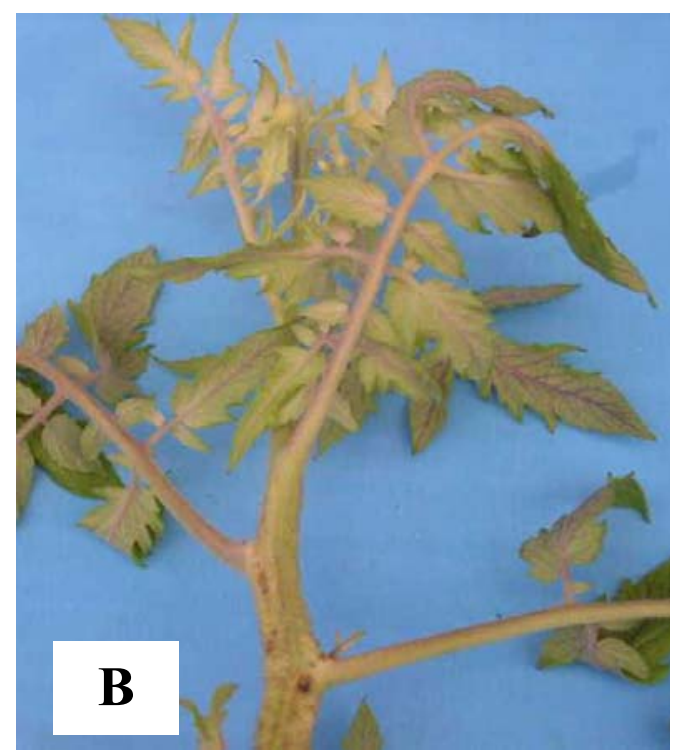

Figura 2. Sintomas de deficiência de zinco em folhas e caules de tomateiro. 
Embora tenha ocorrido frutificação neste tratamento, os frutos revelando-se menores em relação àqueles com suprimento adequado deste nutriente.

Rachaduras nos frutos foi outro sintoma de deficiência de $\mathrm{Zn}$ no tomateiro (Figura 3). A rachadura da epiderme de frutos de tomateiro é caracterizada como um distúrbio fisiológico que costuma estar associado à desequilíbrio hídrico e à bruscas variações de temperatura. Porém, no caso deste experimento, esta característica não pareceu estar associada a nenhum desses fatores já o cultivo foi feito em condições de hidroponia e a temperatura na casa de vegetação não atingiu patamares tão altos por ocasião do experimento. Uma possível causa para o surgimento deste sintoma pode está ligado ao desequilíbrio de nitrogênio e potássio na solução nutritiva.

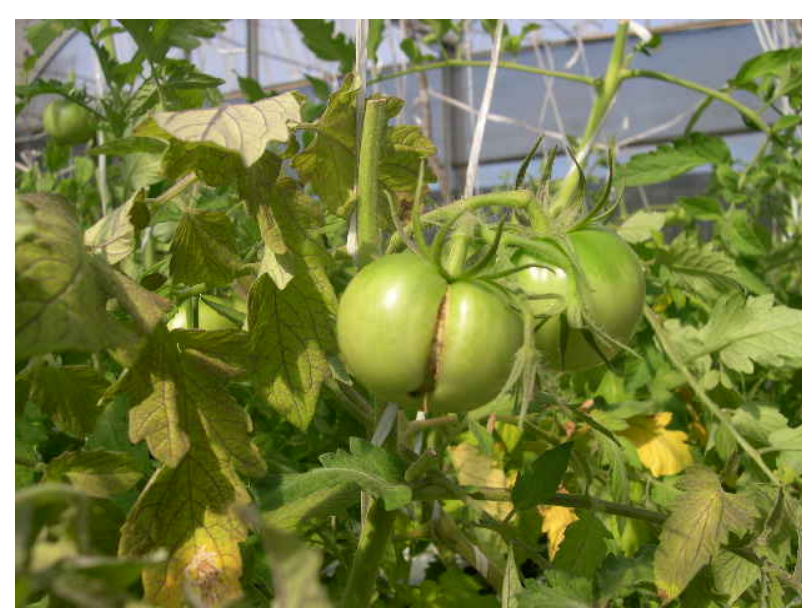

Figura 3. Sintomas de deficiência de zinco em frutos de tomateiro.

Não houve sintoma aparente de deficiência de $\mathrm{B}$ na fase vegetativa, contudo, na fase reprodutiva, observou-se presença de frutos com podridão apical (Figura 4A e 4B), caracterizado pelo aparecimento de tecido necrótico na base distal do fruto, de acordo com Fontes (2003). Plese et al. (1998) relataram a ocorrência dessa anomalia fisiológica como característica de deficiência de boro. Porém, de acordo com Ramon (1990) isso ocorre porque o boro acarreta a deficiência de cálcio, que tem importância fundamental na constituição da parede celular. Assim, ocorre a deterioração das membranas das células do fruto, principalmente os recém-formados, com conseqüente perda de turgor e vazamento do líquido celular (SAURE, 2001). Estudando a omissão de boro em mamona Lange et. al. (2005) observaram evidências da importância deste nutriente na frutificação.

O B foi pouco limitante na fase inicial de desenvolvimento, possivelmente pela baixa necessidade do nutriente nessa fase, onde a quantidade fornecida na fase de adaptação supriu a necessidade da cultura neste período.

Os sintomas de deficiência para os tratamentos onde se omitiu o Mn traduziram-se numa clorose internerval leve nas folhas velhas, sob um reticulado grosso de nervuras que permaneciam verdes (dado não mostrado). Com a intensificação da deficiência, as manchas tornaram-se arroxeadas e as folhas inferiores totalmente amareladas, porém, no geral, o desenvolvimento da planta não pareceu ter sido afetado. Segundo Marschner (1995) os sintomas de deficiência de manganês variam grandemente de uma espécie para outra.

De acordo com Salvador, Moreira e Muraoka (1999) as plantas carentes em Mn apresentam, durante determinado período, desenvolvimento normal, com folhas atingindo dimensões até mesmo maiores. Todavia, com o progredir da carência os sintomas vão se intensificando, coincidindo com as características das plantas observadas no presente experimento.

Tanto nas plantas sem $\mathrm{Cu}$ quanto naquelas sem $\mathrm{Mo}$ não se observou sintomas acentuados de deficiência, apenas sinais tênues que não evoluíram com o aumento no tempo de deficiência. A ausência de sintomas de deficiência de alguns nutrientes testados pode ser devido a baixa exigência dos mesmos para a variedade de tomateiro estudada. É possível que a quantidade dos nutrientes fornecidos na fase de adaptação, embora em baixas concentrações, tenha sido suficiente para suprir a necessidade da cultura. 

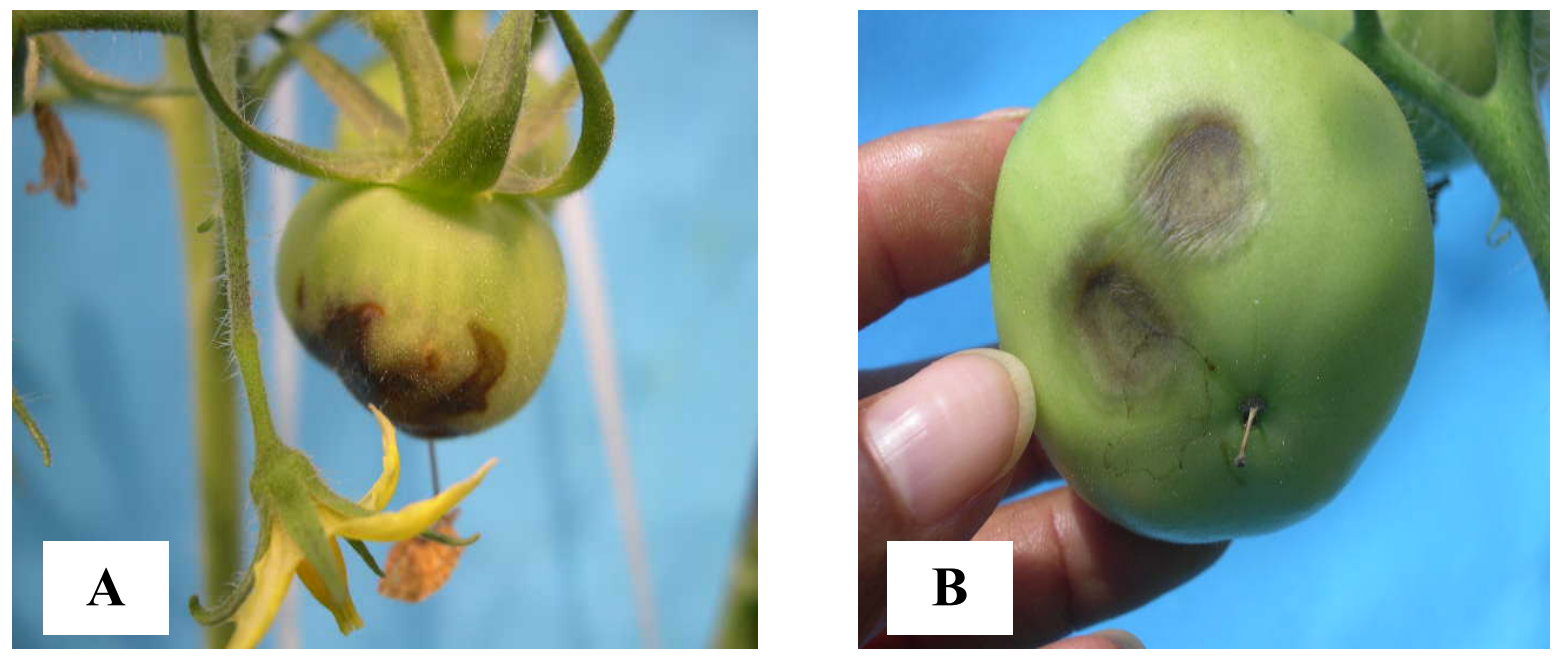

Figura 4. Sintomas de deficiência de boro em tomateiro: podridão do fruto

Outro aspecto que pode ter levado a falta de resposta é a possível contaminação dos reagentes utilizados na pesquisa, considerando que a solução não passou pelo processo de purificação. De acordo com Novais, Neves e Barros (1991) o maior problema associado aos contaminantes diz respeito aos elementos existentes em baixas concentrações na solução.

Fontes (1985) salienta que, além dos produtos químicos usados para o fornecimento de nutrientes às soluções, outras fontes potenciais de contaminação são a água, os recipientes e outros materiais utilizados no preparo das soluções, além do substrato usado para germinação, emergência e início de crescimento das plântulas.

É possível que estes fatores, atuando juntos, tenham contribuído para a não expressão dos sintomas de deficiência dealguns dos micronutrientes estudados. Acredita-se que estudos futuros visando maior controle desses fatores possam responder a estas questões.

De modo geral, a seqüência de surgimento de sintomas foi $\mathrm{Fe}, \mathrm{Zn}, \mathrm{Mn}, \mathrm{Mo}, \mathrm{Cu}, \mathrm{B}$ sendo que a maior intensidade ocorreu nas deficiências de $\mathrm{Fe}$ e Zn.
A omissão do $\mathrm{Fe}$ foi o tratamento que mais afetou o desenvolvimento do tomateiro. Essa seqüência coincide com a ordem de absorção apontada por Rodrigues et al. (2002). A omissão do Zn na solução nutritiva promoveu raquistismo na planta além de rachadura nos frutos, enquanto que na ausência de $\mathrm{B}$ houve ocorrência de frutos com podridão apical.

$\mathrm{O} \mathrm{Fe}, \mathrm{Zn}, \mathrm{Mn}$, Mo e $\mathrm{B}$ resultaram em alterações morfológicas traduzidas como sintomas característicos de deficiência nutricional. Os sintomas ocorreram primeiramente, e com maior intensidade nas deficiências de Fe e Zn. A deficiência de $\mathrm{Zn}$ promoveu a rachadura no fruto.

\section{Agradecimentos}

Os autores agradecem à Universidade Estadual do Sudoeste da Bahia pelo apoio na realização desta pesquisa.

\section{Referências}

CASTEllane, P. D.; SOUZA, A. F.; MESQUITA FILHO, M. D. Culturas olerícolas. In: FERREIRA, M. E.; CRUZ, M. C. P. (Ed.). Micronutrientes na agricultura. Piracicaba: POTAFOS/CNPq. 1991. 374 p. 
EPSTEIN, E. Mineral nutrition of plants: principles and perspectives. New York: John Wiley \& Sons, Inc., 1972. $412 \mathrm{p}$.

FONTES, P. C. R. Podridão apical do tomate, queima dos bordos das folhas de alface e depressão amarga dos frutos em maçã: deficiência de Ca? Horticultura Brasileira, Brasília, v. 21, n. 2, p. 145, 2003.

FONTES, R. L. F. Purificação de soluções nutritivas para indução de deficiência de zinco e cobre, em plantas. Viçosa, 1985. Dissertação (Mestrado em Agronomia). Universidade Federal de Viçosa, Viçosa, 1985.

HOAGLAND, D. R.; ARNON, I. The water: culture method for growing plants without soil. Berkeley: California Agricultural Experimental Station, 1950. (Circular, n. 347).

LANGE, A.; MARTINES, A.. M.; SILVA, M. A.. C.; SORREANO, M. C. M.; CABRAL, C. P. MALAVOLTA, E. Efeito de deficiência de micronutrientes no estado nutricional da mamoneira cultivar Íris. Pesquisa Agropecuária Brasileira, Brasília, v. 40, n. 1, p. 61-67, 2005.

MALAVOLTA E.; VITTI, G. G.; OLIVEIRA A. S. Avaliação do estado nutricional das plantas. Piracicaba: Potafos, 1997.319 p.

MARSCHNER, H. Mineral nutrition of higher plants. London: Academic Press, 1995. 889 p.

MOLINA, E. Fertilización y nutrición de pejibaye para palmito. Research report, Centro de Investigaciones Agronómicas. Universidade de Costa Rica: San José. 1997. 26p.

NOVAIS R. F.;NEVES, J. C. L.; BARROS, N. F. Ensaio em ambiente controlado. In: OLIVEIRA, A.J, GARRIDO, W. E.; ARAÚJO, J. D.; LOURENÇO, S. (Ed.). Métodos de pesquisa em fertilidade do solo. Brasília: EMBRAPASEA, 1991. p. 189-255.

PLESE, L. P. M.; TIRITAN, C. S.; YASSUDA, E. I.; PROCHNOW, L. I.; CORRENTE, J. E.; MELO, S. C. Efeitos de aplicações de cálcio e boro na ocorrência de podridão apical e produção de tomate em estufa. Scientia Agrícola, Piracicaba, v. 55, n. 1, p. 144-148, 1998.

RAIJ, B. V. Fertilidade do solo e adubação. Piracicaba: Potafos, 1991. $142 \mathrm{p}$.
RODRIGUES D. S.; PONTES, A. L.; MINAMI, K.; DIAS, C. T. S. Quantidade absorvida e concentração de micronutrientes em tomateiro sob cultivo protegido. Scientia Agrícola, Piracicaba, v. 59, n. 1, p.137-144, 2002.

ROMHELD, V. Aspectos fisiológicos dos sintomas de deficiência e toxidade de micronutrientes e elementos tóxicos em plantas superiores. In: FERREIRA, M. E.; CRUZ, M. C. P.; RAIJ, B. V.; ABREU, C.A. Micronutrientes e elementos tóxicos na agricultura. Jaboticabal: CNPq; Fapesp; Potafos, p. 71-85. 2001.

RAMON, A. M.; CARPENA-RUIZ, R. O.; GARATE, A.; BEUSICHEN, M.L-van. The effects of short term deficiency of boron on potassium, calcium and magnesium distribuition in leaves and roots of tomato (Lycopersicon esculentum) plants. Development in Plant and Soil Science, Dordrecht, v. 21, n. 41, p. 287-290, 1990.

SALVADOR, J. O.; MOREIRA, A..; MURAOKA, T. Sintomas visuais de deficiência de micronutrientes e composição mineral de folhas de mudas de goiabeira. Pesquisa Agropecuária Brasileira, Brasília, v. 34, n. 9, p. 2, p. 249-255, 1999.

SANTI, A..;CAMARGOS, S. L.; PEREIRA, W. L. M.; SCARAMUZZA, J. F. Deficiências de micronutrientes em sorgo (Sorghum bicolor). Revista de Ciências AgroAmbientais, Mato Grosso, v. 3, n. 1, p. 54-63, 2005.

SAURE, M.C. Blossom-end rot of tomato (Lycopersicon esculentum Mill) - a calcium - or a stess-related disorder? Scientia Horticulturae, Amsterdam, v. 90, n. 3/4, p. 193208, 2001.

SILVEIRA, R. L. V. A.; MOREIRA, A.; TAKASHI, E. N.; SGARBI, F.; BRANCO, E. F. Sintomas de deficiência de macronutrientes e de boro em clones de híbridos de Eucalyptus grandis com Eucalyptus urophylla. Cerne, Lavras, v. 8, n. 2, p. 108-117, 2002.

ZABINI, A.V.; MARTINÉZ, H. E. P.; FINGER, F. L.; SILVA, C. A. Concentração de micronutrientes e características bioquímicas de progênies de cafeeiro (Coffea arábica L.) eficientes no uso de zinco. Bioscience Journal, Uberlândia, v. 23, n. 4, p. 95-103, 2007. 
